\title{
Neutralization with Simultaneous Separation of Metallic Ions from Condensed Water Through Capillary Polypropylene and Cellulose Derivatives ${ }^{\dagger}$
}

\author{
Anca -Maria Cimbru 1,*, Aurelia Cristina Nechifor ${ }^{1}$, Paul Constantin Albu ${ }^{2}$ \\ and Gheorghe Nechifor ${ }^{1}$ \\ 1 Analytical Chemistry and Environmental Engineering Department, Faculty of Applied Chemistry and \\ Material Science, Politehnica University of Bucharest, 1-7 Gheorghe POLIZU str., District 1, \\ 011061 Bucharest, Romania; nechiforus@yahoo.com (A.C.N.); doru.nechifor@yahoo.com (G.N.) \\ 2 IFIN Horia Hulubei, Radioisotopes and Radiation Metrology Department (DRMR), 30 Reactorului Str., \\ 077125 Magurele, Romania; plalbu@yahoo.com \\ * Correspondence: anca.cimbru@weyland-yutani.ro \\ + Presented at the 16th International Symposium "Priorities of Chemistry for a Sustainable Development" \\ PRIOCHEM, Bucharest, Romania, 28-30 October 2020.
}

Published: 13 November 2020

Keywords: composite membranes; neutralization

An interesting and unpredictable environmental issue raises condensing plants, with an average output of 20-100 Kw, producing thermal energy in individual homes, associations or small public buildings. Environmental problems arising from acidic waters containing metallic ions from condensing boilers can be adequately addressed using membrane processes [1-3].

This work deals with simultaneous neutralization and separation of aluminum and copper ion from acidic waters containing metallic ions traces through permeation through capillary composite membranes made of polypropylene with carboxymethyl cellulose (PP/CMC) inclusions.

The ionophore from the composite membrane, a cellulose derivative, carboxymethyl cellulose (CMC) (Figure 1), is one of the most performing ingredients.

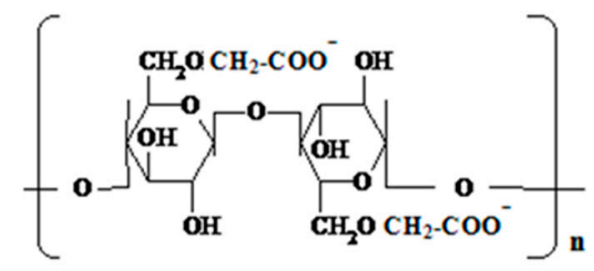

Figure 1. Carboxymethyl cellulose (CMC).

The optimal operating parameters were determined - the flow rate, $\mathrm{pH}$ of the receiving phase and working time. Simultaneously with the quantitative removal of metallics trace ions, an almost neutral $\mathrm{pH}$ is obtained, which is compatible with the natural waters in which it can be dispersed. It is interesting to note that, after $4 \mathrm{~h}$, the performance of the process - especially the neutralizationdecreases, suggesting an osmotic or retro-dialysis process, generated by lowering the $\mathrm{pH}$ gradient.

Acknowledgments: The work has been funded by the Operational Program Human Capital of the Ministry of European Funds through the Financial Agreement 51668/09.07.2019, SMIS code 124705. 


\section{References}

1. Hussam, N.A.A.A.; Cimbru, A.M.; Tanczos, S.K.; Din, I.S.; Cuciureanu, A.; Nafliu, I.M.; Nechifor, G. Ionomolecular separation with composite membranes III. Nitrophenols separation on polysulphone and composite nanoparticles ultrafiltration. Rev.Chim. 2017, 68, 427-434.

2. Hussam, N.A.A.A.; Cimbru, A.M.; Din, I.S.; Tanczos, S.K.; Nafliu, I.M.; Cuciureanu, A. Iono-molecular Separation with Composite Membranes IV. Mono-nitrophenol's pervaporation through polysulfone composite membranes. Mat. Plast. 2017, 54, 353-358.

3. Din, I.S.; Cimbru, A.M., Hussam, N.A.A.A.; Nafliu, I.M.; Tanczos, S.K.; Nechifor, G. Iono-molecular Separation with Composite Membranes V. Nitro-phenol separation on n-alkyl alcohols supported liquid membranes. Rev. Chim. 2018, 69, 1084-1088.

Publisher's Note: MDPI stays neutral with regard to jurisdictional claims in published maps and institutional affiliations.

(C) 2020 by the authors. Licensee MDPI, Basel, Switzerland. This article is an open access article distributed under the terms and conditions of the Creative Commons Attribution (CC BY) license (http://creativecommons.org/licenses/by/4.0/). 